\title{
ARTICLE The H1047R point mutation in p110 alpha changes the morphology of human colon HCT116 cancer cells
}

\author{
G Wan ${ }^{1}$, C Pehlke ${ }^{2}$, R Pepermans ${ }^{3}, \mathrm{JL}$ Cannon $^{4}, \mathrm{D} \mathrm{Lidke}^{5}$ and A Rajput ${ }^{1}$
}

The class IA phosphatidylinositol 3-kinases (PI3K) is involved in controlling changes in cell morphology, which is a highly coordinated cellular event. This event is powered by actin filament polymerization and remodeling. The gain-of-function mutations in the catalytic subunit of p110a of class IA PI3K, which occur in up to one-third of human colorectal cancers (CRCs), are capable of causing dysregulation of cell signaling and thus may result in the alteration in cell morphology and motility and in turn cause cancer metastasis. In vivo studies have demonstrated that cell lines bearing the H1047R point mutation, the most frequent cancerspecific mutation in the kinase domain of $\mathrm{p} 110 a$, are more metastatic than cells carrying wild-type p110a. In the current study, we show that the H1047R in p110a of PI3K decreases F-actin polymerization, increases the formation of filopodia and significantly changes the cell morphology in HCT116 cancer cells. The anti-apoptotic protein B-cell lymphoma 2 (Bcl-2), which is also involved in actin polymerization and cell migration, is downregulated by the H1047R mutation in p110a. Our data suggest that the H1047R mutation in PI3K is responsible for the rearrangement of the cytoskeleton, alteration in cell morphology and enhancing cell motility, and that $\mathrm{Bcl}-2$ may be involved in the H1047R mutation-mediated morphological changes and increased migratory capability.

Cell Death Discovery (2015) 1, 15044; doi:10.1038/cddiscovery.2015.44; published online 19 October 2015

\section{INTRODUCTION}

The dysregulation of the phosphoinositide 3-kinase (PI3K) signaling pathway has been implicated in the progression and metastasis of human cancers, including colorectal cancers (CRCs), and can frequently be induced by genetic mutations in class IA PI3K. In fact, gain-of-function mutations in PI3K have been found in nearly one-third of all human CRCs. ${ }^{1-4}$ Reports have shown that mutations in p110a, the catalytic subunit of PI3K, increase cell migration and the invasive capability of tumor cells. ${ }^{5-6}$ In vivo studies have demonstrated that cells bearing p110a mutations in PI3K were more metastatic than cells carrying wild-type (WT) PI3K in an orthotopic mouse model of colon cancer. ${ }^{7}$ Clinically, studies have shown a significant correlation between the mutations in PIK3CA, the p110a-encoding gene, and the survival of CRC patients. Patients carrying a PIK3CA mutation have a higher rate of disease relapse than patients lacking p110a mutations. ${ }^{8}$ Moreover, it has been reported that these mutations cause a gain of enzymatic fun, ${ }^{3-4}$ which in terms of cancer cell survival, may depend on the type of p110a mutations. ${ }^{5-6}$ These cancerspecific mutations in class IA PI3Ks are located in two specific 'hotspot' regions: in the helical domain or in the kinase domain of the p110a catalytic subunit. These 'hotspot' mutations have been identified in CRCs and account for $80 \%$ of p110a-bearing mutations. $^{2}$ The most frequent mutation in the p110a kinase domain is at position 1047 where histidine is frequently substituted with arginine (H1047R). ${ }^{1}$

Many studies have demonstrated that PI3K is required for the remodeling of actin filaments induced by growth factors, ${ }^{9-10}$ Ras, ${ }^{9-10}$ G-protein-coupled receptors, ${ }^{11}$ integrins ${ }^{12}$ and insulin. ${ }^{13-14}$ It is one of the most important actin cytoskeleton regulators. Thus, any dysregulation involved in the PI3K pathway could affect cellular morphology and motility. Qian et al. ${ }^{15}$ have shown that activation of PI3K alone is sufficient to remodel actin filaments, which then increase cell migration through the activation of protein kinase $B$ (PKB) or serine/threonine-specific protein kinase (Akt) and p70S6K1 in chicken embryo fibroblast (CEF) cells.

Although these findings have shown that the mutations in p110a of PI3K increase cell migration and tumor metastasis, the mechanisms behind these actions are still unclear. Furthermore, there is no direct evidence showing that PI3K mutations are involved in actin cytoskeleton reorganization. In this study, we focused on the relationship between the H1047R point mutation in the p110a kinase domain of PI3K and cell morphology. Our experiments were designed to determine whether the H1047R mutation is capable of: (1) changing the cell morphology of HCT116 cells and (2) reorganizing the actin cytoskeleton, which may explain why CRC cells harboring the H1047R mutation are more metastatic than WT cells. Our results indicate that the H1047R mutation in PI3K decreases F-actin polymerization, while significantly increasing cellular filopodia formation and cell motility, as compared with WT PI3K. Further experiments were designed to investigate what cytoskeletal regulatory factors are involved in the H1047R mutationmediated cell morphological changes. Our data suggest that B-cell lymphoma $2(\mathrm{BCl}-2)$ may be involved in the H1047R mutationmediated cell morphological changes and increased cell migration.

\section{RESULTS}

The H1047R mutation in p110a changes the cell morphology and the appearance of actin filaments in HCT116 cells

The polymerization and organization of actin microfilaments, the major structural filament of cytoskeleton in cells, determine the

\footnotetext{
${ }^{1}$ Division of Surgical Oncology, Department of Surgery, University of New Mexico, Albuquerque, NM, USA; ${ }^{2}$ Spatiotemporal Modeling Center, Comprehensive Cancer Center, University of New Mexico, Albuquerque, NM, USA; ${ }^{3}$ Division of Molecular Medicine, Department of Internal Medicine, University of New Mexico, Albuquerque, NM, USA; ${ }^{4}$ Department of Molecular Genetics Microbiology, University of New Mexico, Albuquerque, NM, USA and ${ }^{5}$ Department of Pathology, University of New Mexico, Albuquerque, NM, USA. Correspondence: A Rajput (arajput@salud.unm.edu)
}

Received 3 August 2015; accepted 7 August 2015; Edited by N Barlev 
overall shape of the cell, ${ }^{16}$ contribute to its internal organization and have a key role in the morphological change of cells. ${ }^{17}$ For certain cell types, this morphological change is indispensable to gain the proper function in the tissue. ${ }^{18,19}$ In other words, the changes in the actin cytoskeleton structure could result in dysregulated function, for example, increasing tumor cell migration. To investigate the effect of the H1047R mutation on cell morphology and actin cytoskeleton structure, we used cell lines harboring either WT or mutant (MUT; H1047R) p110a of PI3K, which were generated by asymmetric deletion of the PIK3CA allele from the CRC parental cell line HCT116. The cells were stained for F-actin with Alexa Fluor 488 Phalloidin and the cell morphology was determined by imaging. The morphology of HCT116 MUT cells was considerably different than that of WT cells (Figure 1). Unlike WT cells, which normally exhibit a round and more clumped morphology, MUT cells became elongated and actin filaments appeared to align along the length of the cell, adopting a more fibroblastic and less clumped morphology.

Cell protrusion involves the extension of cellular membranes. Its physical backbone is constituted by actin filaments. It usually occurs in response to the stimulation of chemoattractive signals in the microenvironment. However, some cells extend protrusions in a probing, exploratory manner in the absence of directional stimulation. ${ }^{20}$ To understand whether the H1047R mutation could also affect the behavior of cell protrusions in the absence of directional stimulation, we tracked the motion of living HCT116 WT and MUT cells expressing Lifeact-green fluorescent protein $(\mathrm{GFP})^{21}$ under high magnification (Figure $1 \mathrm{~b}$ and Supplementary Movies 1 and 2). The WT cells exhibited a rounded shape with no obvious morphological polarity and their protrusions seemed to be random. On the other hand, however, HCT116 MUT cells displayed an elongated shape with stronger protrusion points primarily at two end sides of the cells (Figure 1b; red arrows).

The H1047R mutation in p110a induces a change in cell projections and increases the formation of actin filopodia

Cell projections are dynamic and morphologically varied extensions of the plasma membrane, supported by the actin cytoskeleton, which are essential for cell migration. The higherorder actin-based structures are lamellipodia and filopodia. Filopodia are thin membrane protrusions that are oriented with the barbed end of their actin filaments towards the protruding membrane and extend beyond the leading edge of lamellipodia in migrating cells. ${ }^{22}$ Our image analysis data showed that WT and MUT HCT116 cells display different cell projections (Figure 2). To quantify the filopodia projections, we generated a Matlab script as described in a previous report. ${ }^{23}$ By comparing the value of $R$, which measures the surface roughness of cells, we found that MUT cells had lower $R$-values ( 0.56 on average), whereas $R$-values of WT cells were closer to 1 ( 0.91 on average; Figure 2a). The evaluation of the statistical significance on the numbers of filopodia protrusions around the cell surface of WT and MUT cells, were significant $(P<0.001)$ (Figure $2 b)$. This difference corresponds to our finding that MUT cells have much more and longer filopodia, which are protruding out of the cell membrane, compared with WT cells.

The H1047R mutation in $\mathrm{p} 110$ a decreases actin polymerization and increases cell migratory capability

F-actin is a critical player in many cellular functions, ranging from cell motility and the maintenance of cell shape and polarity to the regulation of transcription. It is a linear actin polymer and is formed by polymerization of monomeric G-actin and the dynamics of actin polymerization and depolymerization is critical for cell migration. ${ }^{16}$ To test whether the H1047R mutation in p110a affects the levels of actin polymerization, F-actin levels were measured in HCT116 parental, WT and MUT cells by flow cytometry (Figure 3). The results indicated that the level of F-actin in parental and MUT cells was significantly decreased as compared with that in WT cells. Moreover, MUT cells were found to have increased motility as compared with WT cells when assayed in a wound-healing experiment (Figure 4).

Activation of PI3K by H1047R mutation in p110a contributes to changes in cell morphology

It has been reported that the H1047R mutation in $\mathrm{p} 110 \mathrm{a}$ will result in constitutive activation of $\mathrm{PI} \mathrm{K}^{2}{ }^{2}$ Activation of $\mathrm{PI} 3 \mathrm{~K}$ directly regulates downstream signal transduction through excessive production of phosphatidylinositol $(3,4,5)$-trisphosphate (Ptdlns $\left.(3,4,5) P_{3}\right)\left(\mathrm{PIP}_{3}\right)$. The important second messenger $\mathrm{PIP}_{3}$, is virtually undetectable in quiescent cells and is only transiently produced in the plasma membrane of stimulated cells by the class- $1 \mathrm{PI} 3 \mathrm{Ks}^{24}$ Thus, the increased PI3K kinase activity by mutated $\mathrm{p} 110 \mathrm{a}$ will result in an overabundance of $\mathrm{PIP}_{3}$ in cells. ${ }^{1,4,8}$ In order to compare PI3K activity in HCT116 WT and MUT cells, we measured their intracellular levels of $\mathrm{PIP}_{3}$ and phosphorylation levels of Akt, one of the most important downstream substrates of PI3K signaling pathway. The MUT cells showed both higher levels of $\mathrm{PIP}_{3}$ (Supplementary Figure 1) and phosphorylation of Akt (Supplementary Figure 2) as compared with WT cells.

The PI3K signaling pathway can be negatively regulated by the tumor suppressor PTEN (phosphatase and tensin homolog). PTEN converts $\mathrm{PIP}_{3}$ in the cytoplasm to $\mathrm{PIP}_{2}$, thereby directly antagonizing the activity of $\mathrm{PI} 3 \mathrm{~K}^{25}$ Inactivation of PTEN also results in constitutive activation of the $\mathrm{PI} 3 \mathrm{~K}$ pathway and a subsequent increase in protein synthesis, cell cycle progression, migration and survival. ${ }^{25,26}$ Thus, the PTEN status is important for the experimental setting, it has to be normal and the expression level was required to be equable in these isogenic cell lines of HCT116 cells. Our results showed no difference in the level of PTEN in parental, WT and MUT HCT116 cells (Supplementary Figure 2) and that HCT116 cell line possesses WT PTEN (data not show).

In addition, it is known that p85, the regulatory subunit of PI3K, has an important role in stabilizing the catalytic subunit $\mathrm{p} 110 .^{27}$ Therefore, we also measured the expression levels of p110a and p85a in all the cell lines and found similar expression level of p110a in all three cell lines, but higher expression level of p85a in parental and MUT cells than in WT cells (Supplementary Figure 2).

Next, we investigated whether the H1047R mutation-mediated gain of function of PI3K is directly involved in the morphologic change of MUT cells. To do this, A66 was utilized because it exhibits greater specificity in inhibiting $\mathrm{p} 110 a$ as compared with other p110a inhibitors. Thus, other class-1 PI3Ks, class-II PI3Ks, class-III PI3K and PI4Ks (phosphoinositide 4-kinases) are unaffected and maintain their function in growth factor signaling. ${ }^{28}$ MUT cells were either treated or not treated with $1 \mu \mathrm{M}$ of $\mathrm{A} 66$ at several time points $(0,0.25,0.5,1,6,12$ and $24 \mathrm{~h})$. Inhibition of A66 on kinase activity was confirmed by the immunoblotting analysis of the phosphorylation level of Akt, with maximum inhibition reached around $6 \mathrm{~h}$ (Figure 5a). HCT116 MUT, treated for $6 \mathrm{~h}$ with the inhibitor, adapted a cellular morphology similar to that of WT cells (Figure 5b). We use the shape factor to evaluate the overall morphologic alteration of HCT116 MUT cells at $6 \mathrm{~h}$ inhibition of A66. Shape factors were determined and are summarized in Figure 5c. Untreated cells had an average shape factor value of 0.43 , and displayed an elongated morphology. In contrast, cells treated for $6 \mathrm{~h}$ with $1.0 \mu \mathrm{M}$ of $\mathrm{A} 66$ had a larger shape factor (average 0.86 ), and had the morphology similar to that of WT cells (average shape factor: 0.86 ). 
a
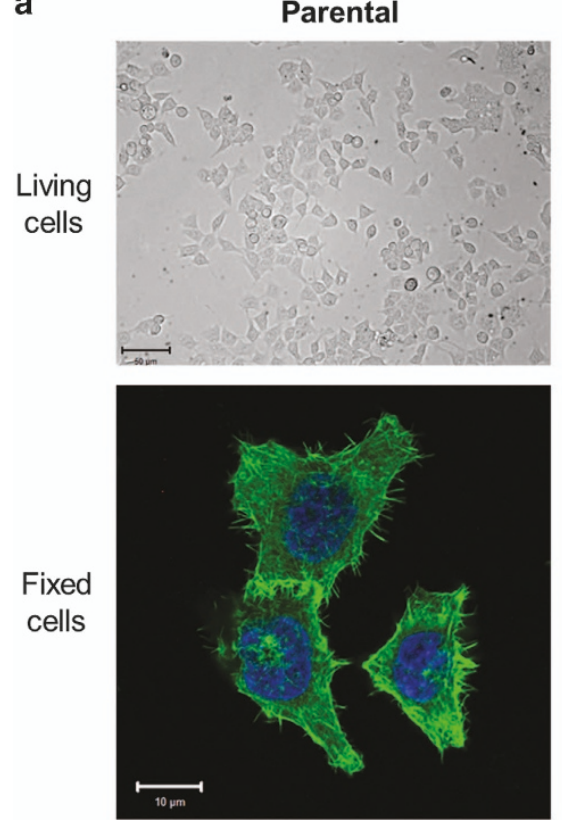

b
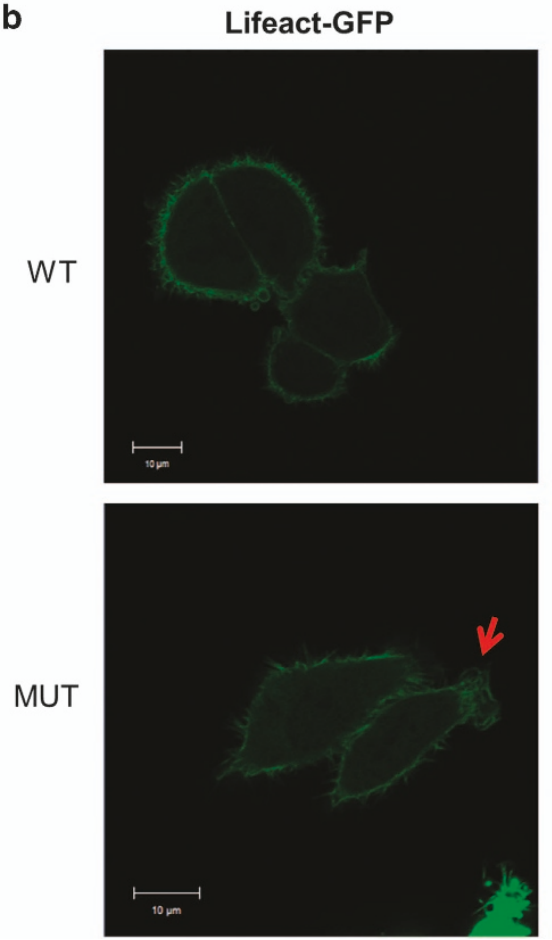

MUT
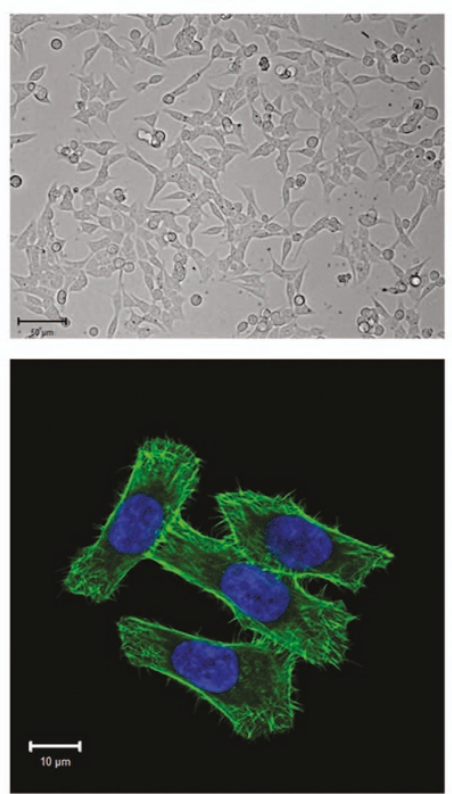

DIC
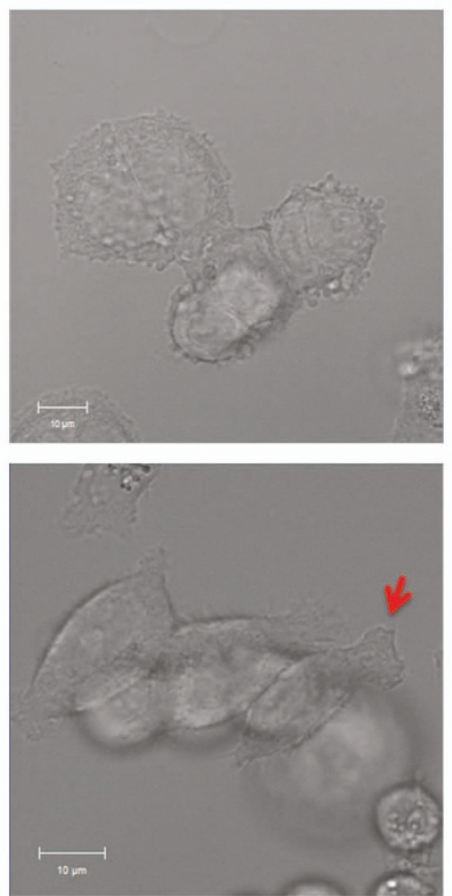

WT
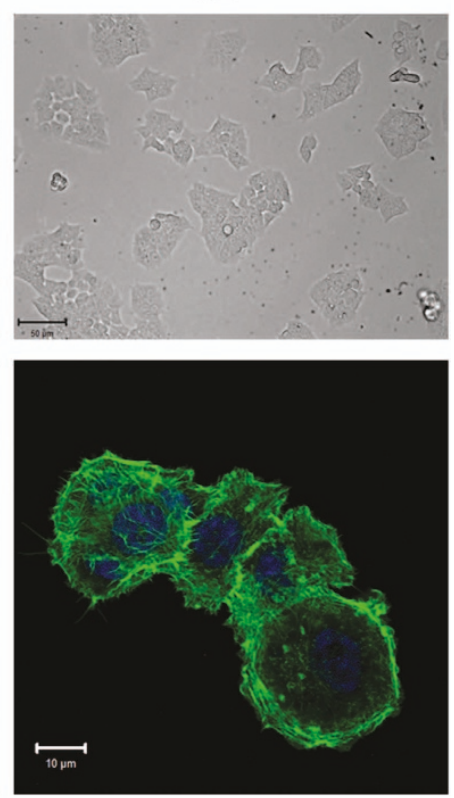

Merge
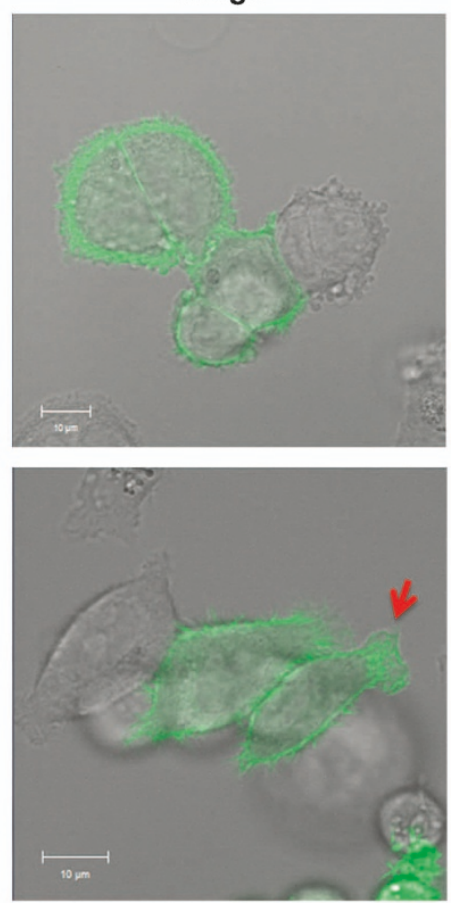

Figure 1. Cell morphology of HCT116 cells is altered by the H1047R mutation in the p110a kinase domain of PI3K. (a) Cell morphology of HCT116 cells. Top panel: cell morphologies of live parental, WT and MUT HCT116 cells captured at a $\times 20$ magnification. Bottom panel: confocal images parental, WT and MUT HCT116 cells captured at a $\times 63$ magnification. Cells were fixed and stained for F-actin (green). Nuclei were stained with DAPI (blue). (b) Movement and morphology of live HCT116 WT (top) and MUT (bottom) cell at a $\times 40$ magnification. Cells were transfected with Lifeact-GFP and cultured in a chambered cover glass dish for $24 \mathrm{~h}$, and fluorescence and DIC images were acquired over $20 \mathrm{~min}$.

The H1047R mutation in p110a decreases Bcl-2 expression, which may contribute to reduced actin polymerization and remodeling of cytoskeleton

It is unclear how the single H1047R amino-acid substitution in the kinase domain of p110a can markedly decrease actin polymerization in HCT116 cells, resulting in a change in cell morphology. Recently, Ke et al. ${ }^{29}$ found that $\mathrm{BCl}-2$ inhibits cell adhesion, spreading and motility by enhancing actin polymerization. Therefore, it was very interesting whether the H1047R mutation in p110a can affect the level of Bcl-2 in HCT116 cells. We compared the endogenous level of Bcl-2 in HCT116 WT and MUT cells by immunoblotting analysis. We found that cells bearing WT-p110a possess a higher expression level of $\mathrm{Bcl}-2$ as compared with that in MUT cells (Figure 6a). Next, we tested whether and how the $\mathrm{Bcl}-2$ levels in HCT116 WT cells can be altered by the increased expression of WT- or H1047R-p110a. HCT116 WT cells transfected with Tet-On 3G-inducible plasmids, pTRE3G-BI-mCherry/ p110a $a^{W T}$ or pTRE3G-BI-mCherry/p110a $a^{H 1047 R}$, were cultured for 
a
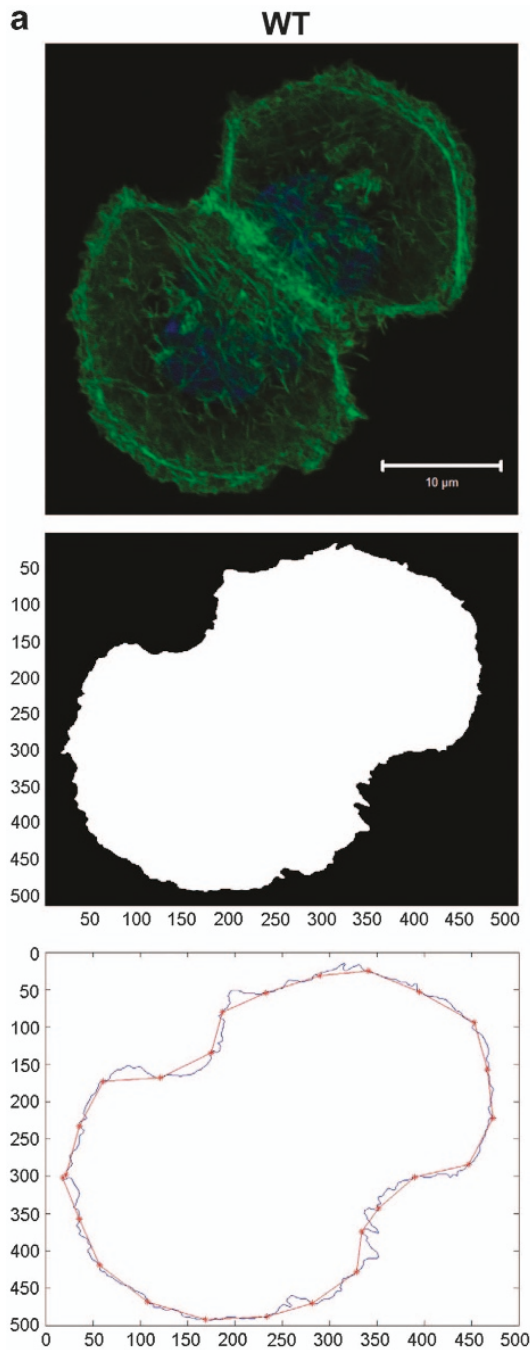

MUT
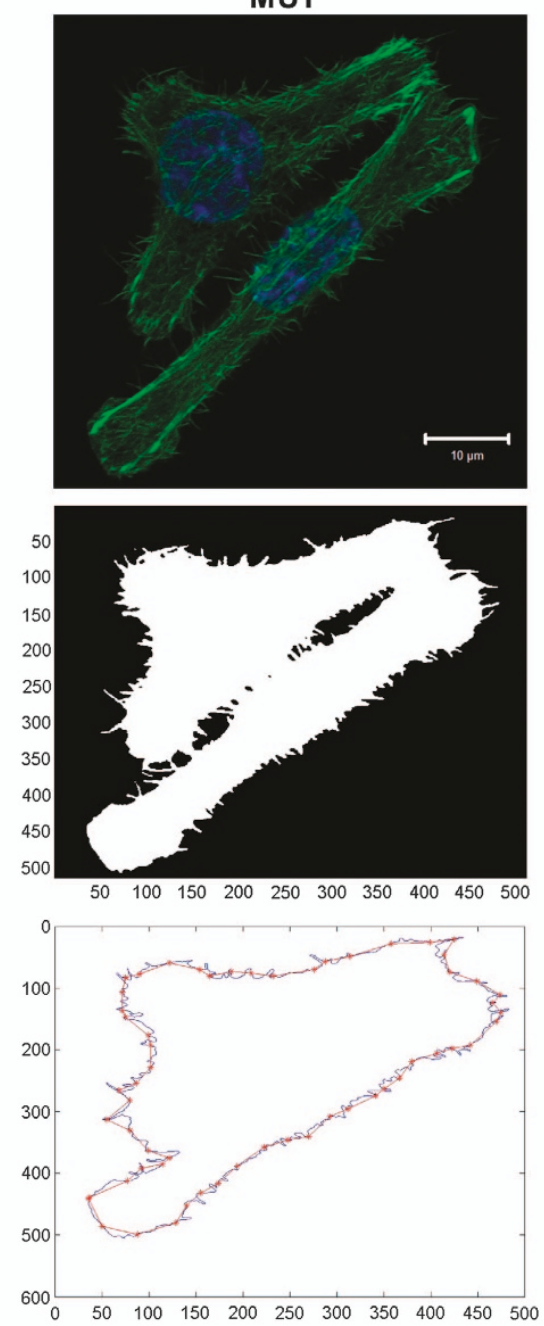

b

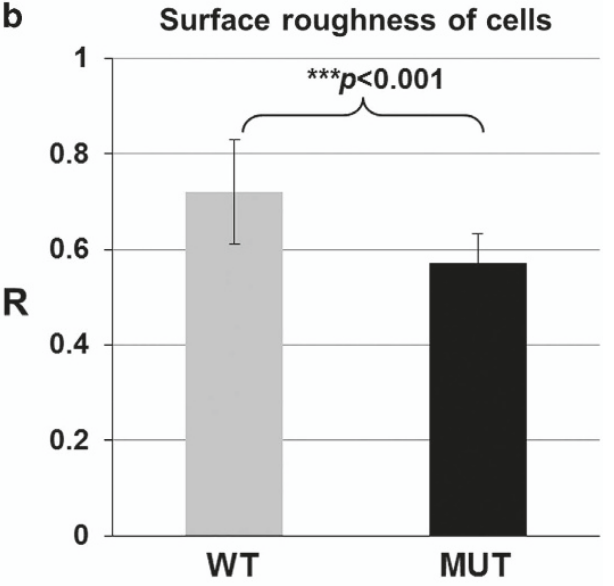

$R=\frac{\Sigma \text { Line Segment Length }}{\Sigma \text { Cell Border Length }}$

Figure 2. The H1047R mutation in the p110a kinase domain of PI3K increases the number of filopodia-like actin filaments. (a) Quantification of filopodia-like actin filaments in HCT116 WT and MUT cells. Original confocal images of F-actin-stained (green) HCT116 WT (top panel, left) and MUT cells (top panel, right), cell masks created by Matlab (middle panel), and Matlab-drew cell outline or border line (blue) as well as cell straight line segment (red; bottom panel), which are uniform 5- $\mu \mathrm{m}$ length and were superimposed along the cell border line. The cell roughness $(R)$ was used as a surrogate measure for the estimated density or amount of filopodia around the cell borders, which are the ratios between the sum of the lengths of the line segments and the total cell border length (b), the summary of cell surface roughness $(R)$. Over 40 cells of each cell line were used for the analysis. Statistical analysis was performed using a two-tail Student's $t$-test, where $P=0.001$.

$24 \mathrm{~h}$ in the medium containing 0,10 and $100 \mathrm{ng} / \mathrm{ml}$ of doxycycline (DOX), respectively. The levels of $\mathrm{Bcl}-2$ were measured by immunoblotting analysis and quantified using Imaging Lab Software (Bio-Rad laboratories, Hercules, CA, USA). Figure $6 \mathrm{~b}$ shows that $\mathrm{Bcl}-2$ expression was increased following the induced expression of WT-p110a, whereas the overexpression of H1047Rp110a had no effect. Furthermore, we examined whether the inhibition of p110a alters the expression of Bcl-2. HCT116 MUT cells showed an A66-dose-dependent increase in $\mathrm{Bcl}-2$ expression, however, WT cells showed an A66-dose-dependent decrease in $\mathrm{Bcl}-2$ expression (Figure $6 \mathrm{c}$ ).

In order to determine whether $\mathrm{Bcl}-2$ is directly involved in the H1047R-p110a-mediated cell morphological changes, HCT116 MUT cells were transfected with pUNO1 or pUNO1-Bcl-2 plasmids. Overexpression of $\mathrm{BCl}-2$ resulted in HCT116 MUT cells adapting a more circular shape and caused them to clump together (Figure 7a). Moreover, overexpression of $\mathrm{Bcl}-2$ delayed the wound closure in HCT116 MUT cells (Figure 7b).

These data thus suggest that the H1047R mutation in p110a of $\mathrm{PI3K}$ decreases $\mathrm{BCl}-2$ expression levels and that the downregulation of $\mathrm{Bcl}-2$ is involved in the H1047R-p110amediated cell morphological changes and increased migratory capability of HCT116 cells.

\section{DISCUSSION}

Recent studies have demonstrated that the gain of function induced by mutations in PI3K not only results in enhanced migration and invasion of cancer cells, but also metastasis of cancer in vivo. ${ }^{4-6}$ Guo et al. ${ }^{7}$ have shown that in vivo, CRC cells bearing the H1047R mutation in $\mathrm{p} 110 a$ of $\mathrm{PI} 3 \mathrm{~K}$ have a higher rate of metastasis to the liver than cells bearing WT PI3K. Our current study has shown that the H1047R mutation in p110a of PI3K causes CRC HCT116 cells to become more motile compared with the WT cells. This increased migration may contribute to metastatic capability. We have also confirmed that one of these important gain-of-function mutations, H1047R, in the catalytic subunit p110a of $\mathrm{PI} 3 \mathrm{~K}$, increases the production of $\mathrm{PIP}_{3}$ and the phosphorylation of Akt. These results are consistent with findings in previous reports. ${ }^{6,7}$ Importantly, our results show that the 
H1047R mutation decreases F-actin polymerization, increases filopodia formation and results in a marked change in cell morphology. This morphological change, however, was abrogated by the inhibition of p110a. The change in cell morphology, mediated by the H1047R mutation in p110a, may grant HCT116 MUT cells their increased ability to migrate. This is, to the best of our knowledge, the first demonstration that the H1047R kinase

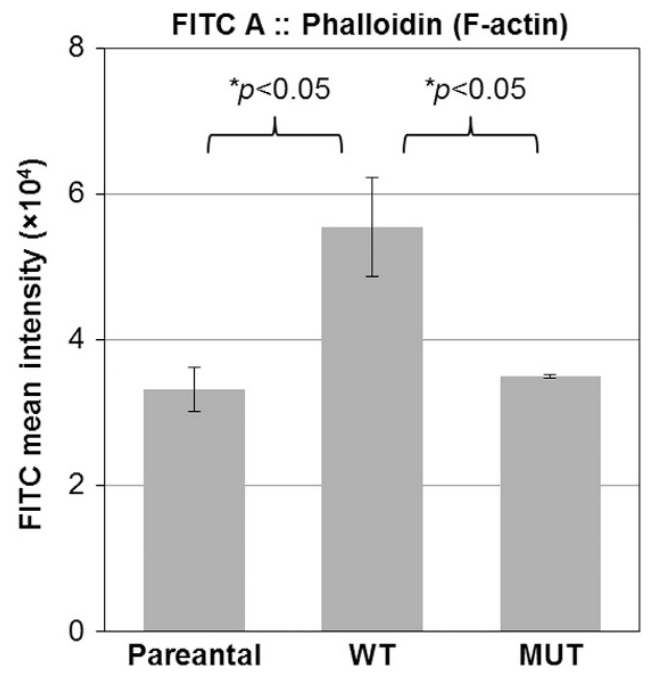

Figure 3. The H1047R mutation in the $\mathrm{p} 110$ a kinase domain of $\mathrm{PI} 3 \mathrm{~K}$ decreases the actin polymerization. Cells were stained with Alexa Flour 488-conjugated phalloidin and their mean FITC::Phalloidin intensities were measured by flow cytometry. The mean intensities of FITC (Alexa Flour 488)::Phalloidin indicate F-actin contents. The experiment was repeated three times, and each experiment included at least two duplications. This indicates that F-actin content in WT cells was significantly higher than that in parental or MUT cells (two-tail Student's $t$-test, $P<0.05$ ). mutation in 110 a of PI3K is related to the reorganization of the actin cytoskeleton and the resulting changes in cell morphology, which possibly contributes to the enhanced migratory capacity. Furthermore, we have found that downregulation of $\mathrm{Bcl}-2$ can be caused by the H1047R mutation in $\mathrm{p} 110 \mathrm{a}$ and that this downregulation may be involved in the H1047R mutationinduced alteration of actin cytoskeleton and cell motility.

Cell migration is the key cellular feature of cancer metastasis. It is a highly coordinated cellular event that is powered by actin polymerization and remodeling of actin filaments. ${ }^{16,30}$ Studies have suggested that higher levels of actin polymerization result in lower cell motility. ${ }^{15,31}$ We have shown that F-actin levels were decreased in HCT116 parental and MUT cells compared with WT cells (Figure 3 ). This could explain why the H1047R mutation in p110a of PI3K can increase cell motility.

It is known that in order for cells to change their morphology or acquire a migratory phenotype, they must undergo extensive actin cytoskeleton remodeling, which is regulated by over 100 actin-binding proteins and controlled by many cellular signaling transduction mediators. $\mathrm{PI} 3 \mathrm{Ks}$ and $\mathrm{BCl}-2$ are two important players in regulating cell survival through two distinct cell signaling pathways. ${ }^{32-34}$ However, both of them have also been reported to be involved in cell adhesion, cytoskeletal rearrangement and cell motility. ${ }^{29-34}$ These functions can be dissociated from their survival or anti-apoptotic function. Ke et al. ${ }^{29}$ reported that $\mathrm{Bcl}-2$ enhances actin polymerization and proposed a mechanism for the enhanced actin polymerization by $\mathrm{Bcl}-2$ : $\mathrm{Bcl}-2$ expression may regulate the gelsolin-mediated activity of F-actin severing. ${ }^{31}$ Interestingly, it was reported that overexpression of $\mathrm{BCl}-2$ results in cells acquiring a rounded shape and increased actin expression in the prostate cancer cell line PC $12 .{ }^{35}$ This agrees with our finding that WT-p110a HCT116 cells possess high levels of Bcl-2 and display more circular cell morphology compared with MUT cells. Moreover, there is data demonstrating that inhibition of PI3K result in a $45 \%$ decreases in $\mathrm{Bcl}-2$ promoter activity, and the activation of $\mathrm{Bcl}-2$ promoter is controlled by Akt/cAMP-response
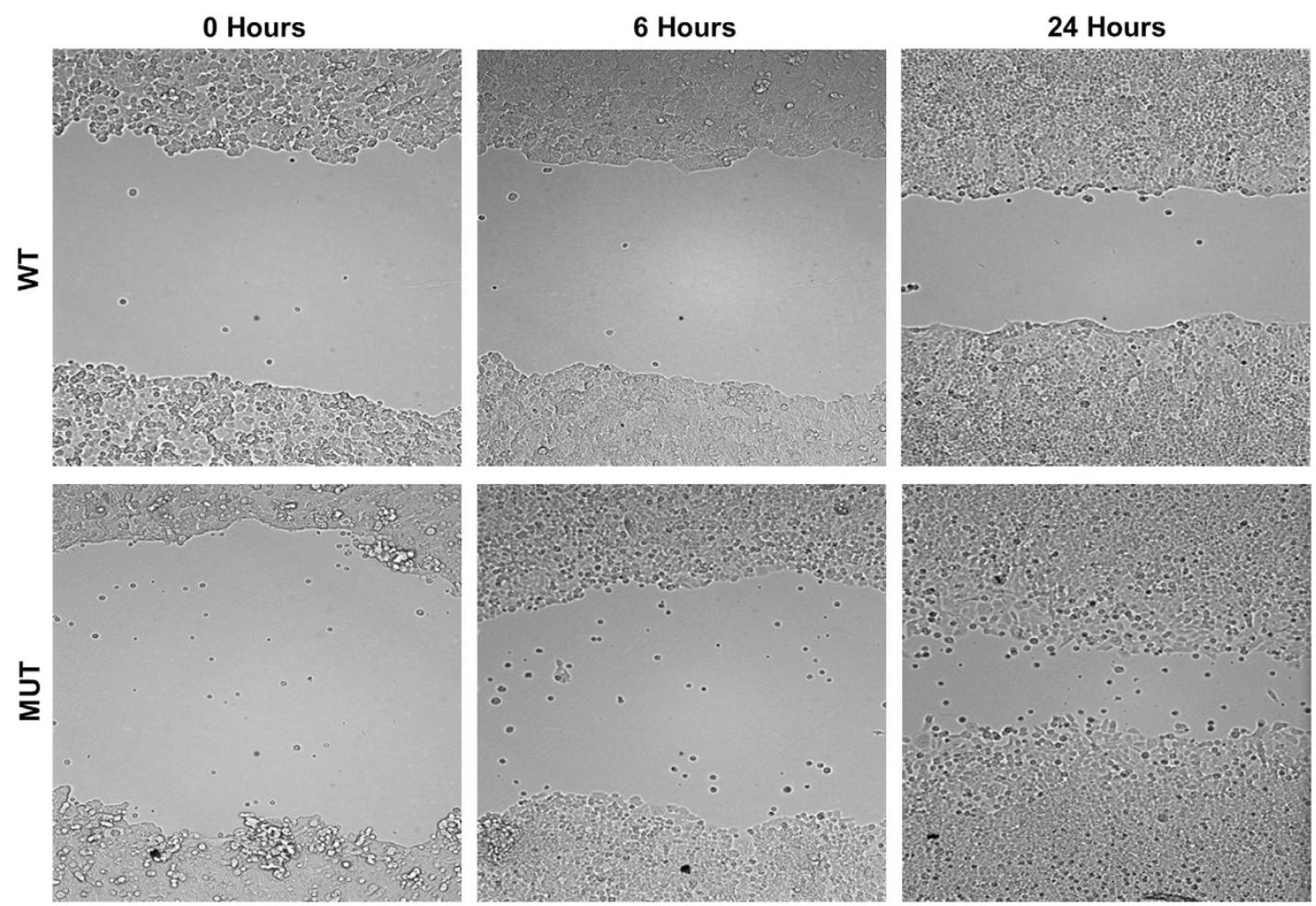

Figure 4. The H1047R mutation in the p110a kinase domain of PI3K increases cell migration. The migratory capability of HCT116 WT and MUT cells was measured by wound-healing assay. HCT116 MUT cells revealed the faster wound closure compared with WT cells at $24 \mathrm{~h}$. 


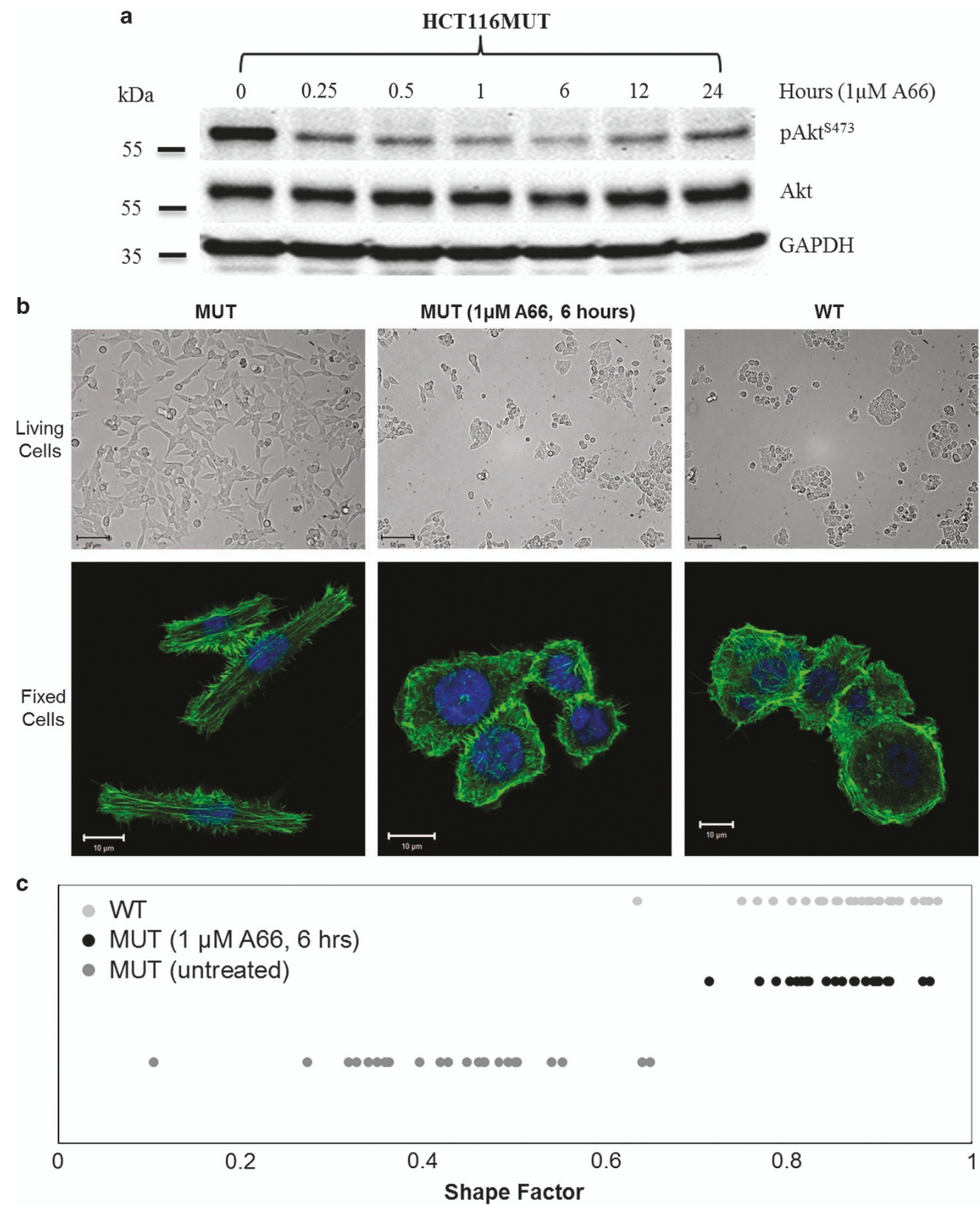

Figure 5. Cell morphology of HCT116 MUT cells resemble that of WT cells following inhibition of PI3K-p110a. (a) Time-dependent inhibition of A66 on PI3K-p110a. HCT116 MUT cells were cultured in $1 \mu \mathrm{M}$ A66 containing medium for the indicated time points and immunoblotting analysis was used to determine the phosphorylation of Akt. The maximal inhibition effect was at $6 \mathrm{~h}$. (b) Cellular morphology of HCT116 MUT cells in the presence or absence of A66. HCT116 MUT cells were cultured on coverslips and incubated for $6 \mathrm{~h}$ in the medium presence or absence of $1 \mu \mathrm{M}$ A66. Top panel: cell morphology of the living MUT $( \pm$ A66) and WT HCT116 cells $(\times 20$ magnificence). Bottom panel: confocal images of fixed MUT ( \pm A66) and WT HCT116 cells ( $\times 63$ magnificence). For the confocal images, cells were fixed and stained for F-actin (green) and nuclei (blue). (c) Shape factor of HCT116 MUT cells in the presence or absence of A66. Quantitative analysis of the cell shape of MUT cells, treated with/without A66, was conducted using shape factors. Shape factors were determined by the area, perimeter and circularity of individual cells. Untreated WT cells were used as the control. For each sample, at least 20 individual cells were included in this assay.

element-binding activity. ${ }^{36}$ In other words, intracellular $\mathrm{Bcl}-2$ expression could potentially be altered by either inhibition or dysfunction of PI3K. Our data suggest that H1047R mutation in p110a mediates the downregulation of Bcl-2 (Figure 6a). Furthermore, several reports have shown that loss of $\mathrm{BCl}-2$ expression correlates with tumor recurrence in $\mathrm{CRC} .{ }^{37} \mathrm{~A}$ high level of $\mathrm{BCl}-2$ is also predictive of relapse-free survival of stage II CRC. ${ }^{38}$ These findings suggest that the H1047R mutation enhanced liver metastasis of $\mathrm{CRC}^{7}$ may be related to the low level of $\mathrm{BCl}-2$ expression. In addition, our results show that $\mathrm{BCl}-2$ levels were upregulated in HCT116 WT cells upon overexpression of WTp110a in DOX dose-dependent manner. However, overexpression 
a
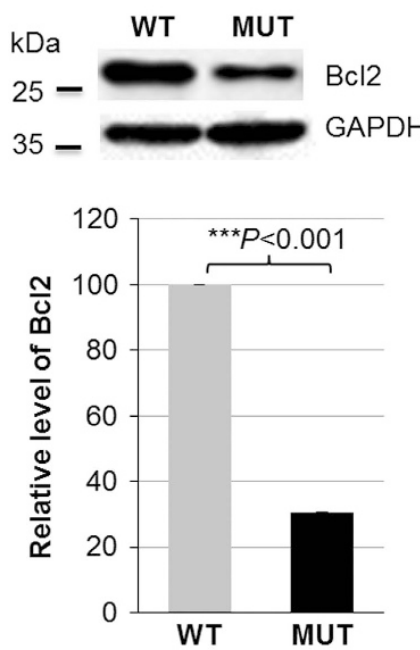

b

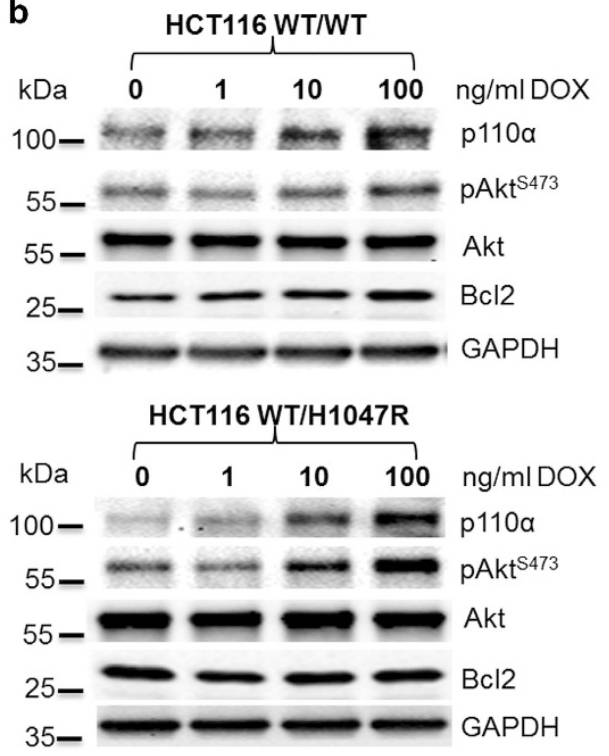

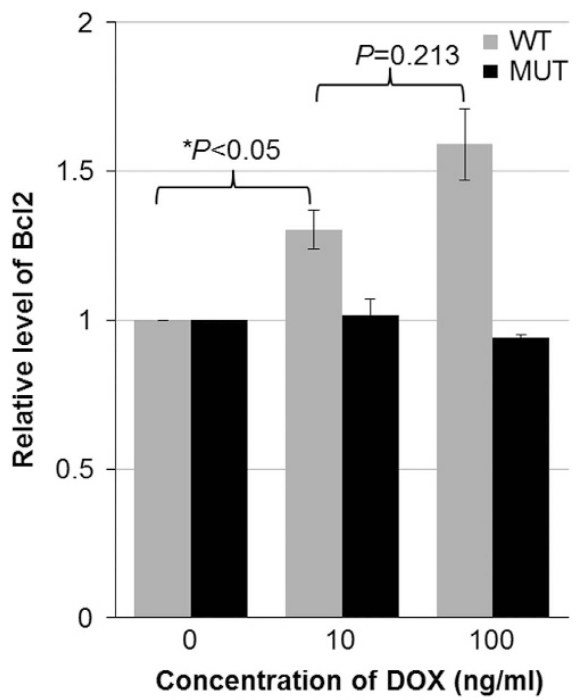

c

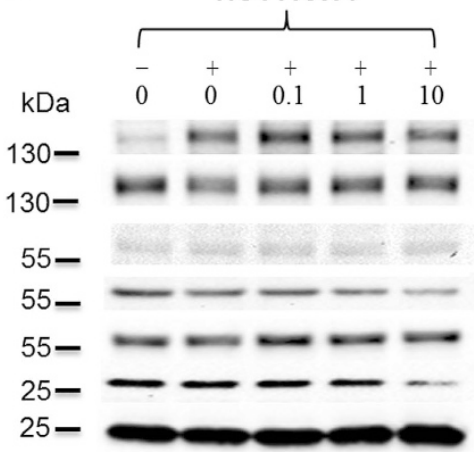

HCT116MUT

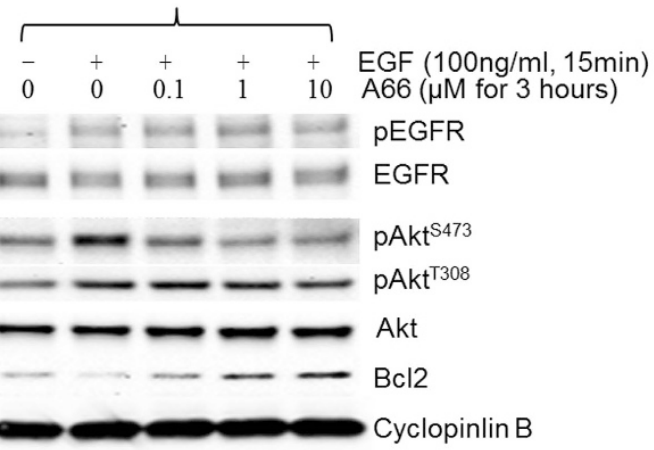

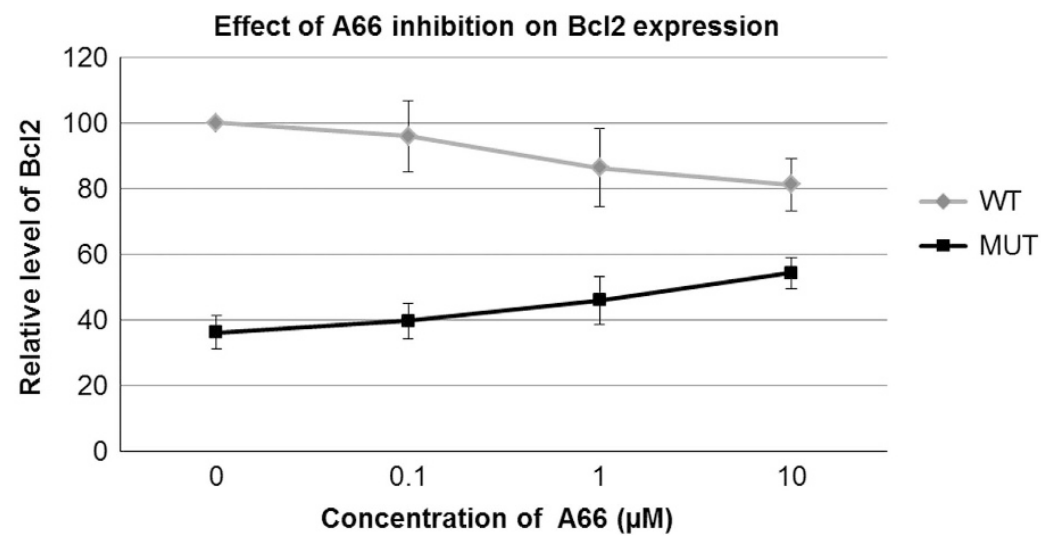

Figure 6. The H1047R mutation in the p110a kinase domain of PI3K affected Bcl-2 expression level. (a) Endogenous level of Bcl-2 in HCT116 WT and MUT cells. Endogenous level of Bcl-2 in HCT116 WT and MUT cells was measured by immunoblotting analysis (top). The graph shows the quantification of $\mathrm{BCl}-2$ bands normalized by glyceraldehyde 3-phosphate dehydrogenase (GAPDH) for three individual experiments (bottom). The Bcl-2 level in HCT116 WT cells was at least three times higher than in HCT116 MUT cells. (b) Effects of overexpressing WT-p110a and H1047R-p110a on Bcl-2 levels. HCT116 WT cells, which were transfected with the Tet-On 3G-inducible plasmids pTRE3G-BI-mCherry/ p110a $a^{\text {WT }}$ or pTRE3G-BI-mCherry/p110a ${ }^{\text {H1047 }}$, were cultured in the medium containing indicated concentration of doxycycline (DOX; left). Their $\mathrm{BCl}-2$ levels were measured by immunoblotting analysis (left). The graph shows the quantifications of $\mathrm{Bcl}-2$ bands of two different clones from the individual cell lines (right). Overexpression of WT-p110a resulted in a DOX dose-dependent increase in Bcl-2 levels, however, Bcl-2 levels were not verified by overexpression of H1047R-p110a. (c) Effect of p110a inhibition on Bcl-2 levels. HCT116 WT and MUT cells were serum starved overnight, subsequently cultured in the presence of A66 at the indicated concentrations for $3 \mathrm{~h}$, and then followed by $100 \mathrm{ng} / \mathrm{ml}$ EGF stimulation for 20 min. Immunoblotting analysis was used to measure Bcl-2 levels in HCT116 WT (left) and MUT (right) cells. The graph shows the quantifications of expression Bcl-2 levels in HCT116 WT and MUT cells on treatment of A66 (bottom panel). Data are the average of two independent experiments. Bcl-2 levels in HCT116 MUT cells was A66 dose-dependently increased, however, an A66 dose-dependent decrease was observed in HCT WT cells. 
a

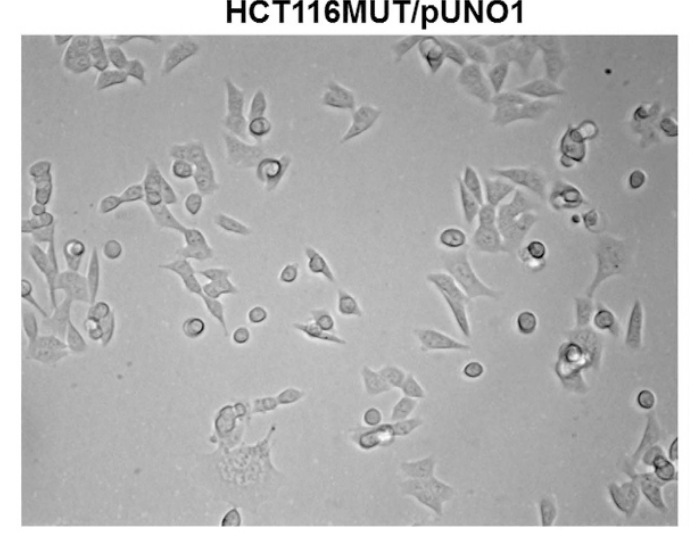

HCT116MUT/pUNO1-Bcl2

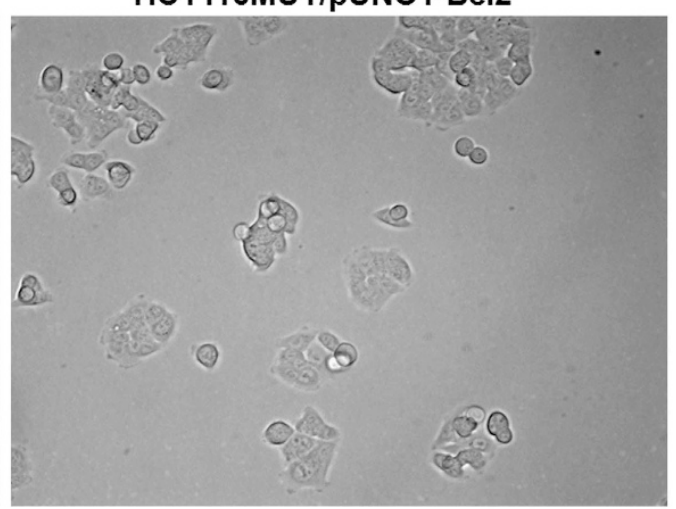

b
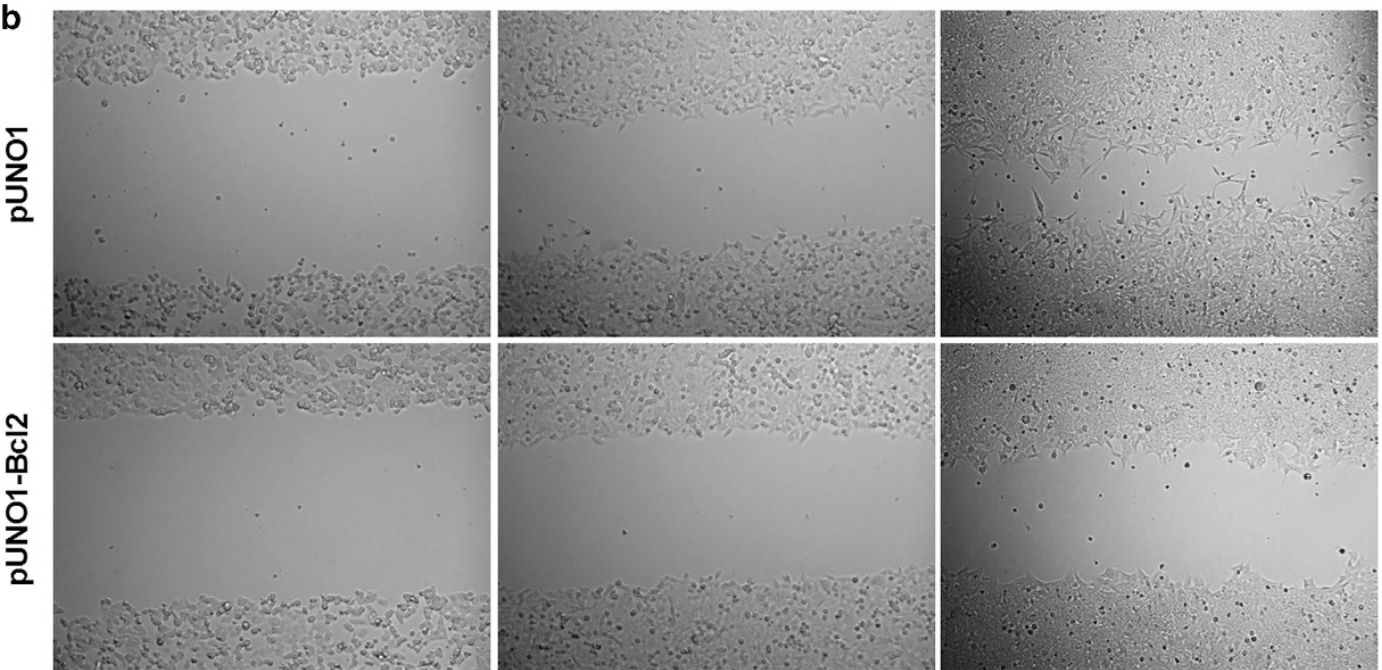

0

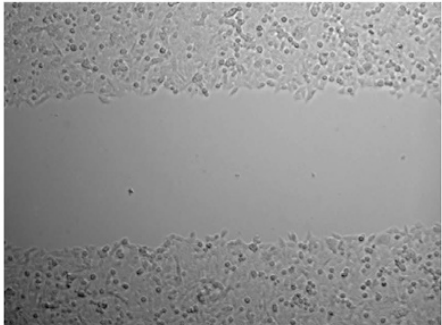

$12 \mathrm{hrs}$

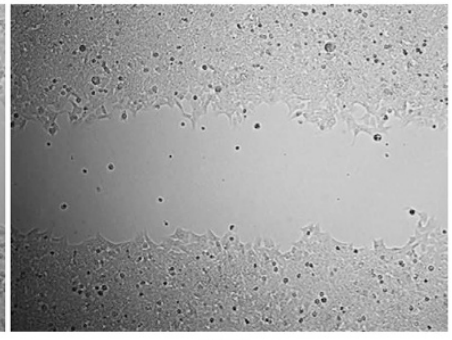

24hrs

Figure 7. Overexpression of $\mathrm{Bcl}-2$ altered cell morphology and delayed cell migration of HCT116 MUT cells. (a) Overexpression of Bcl-2 changed cell morphology of HCT116 MUT cells. HCT116 MUT cells were stable transfected with the pUNO1 or pUNO1-Bcl-2 plasmid and imaged at $\times 20$ magnification. Cell morphology became rounded and cells aggregated together when Bcl-2 was overexpressed. (b) Cell migration of HCT116 MUT cells was inhibited by Bcl-2 overexpression. HCT116 MUT cells were stably transfected with the pUNO1 or pUNO1$\mathrm{BCl}-2$ plasmid. Wound-healing assay was performed as described in the Materials and methods. Overexpression of Bcl-2 delayed the wound closure at 12 and $24 \mathrm{~h}$ in the stable transfected HCT116 MUT cells as compared with the vector transfected HCT116 MUT cells.

of H1047R-p110a had no effect on Bcl-2 levels, although DOX dose-dependent overexpression of H1047R-p110a resulted in hyperactivity of $\mathrm{PI} 3 \mathrm{~K}$ (higher phosphorylation level of Akt; Figure $6 \mathrm{~b}$ ). On the other hand, cellular Bcl-2 levels of HCT116 WT cells were decreased through A66-mediated inhibition of p110a, whereas A66 treatment of HCT116 MUT cells resulted in a dose-dependent increase in $\mathrm{Bcl}-2$ levels (Figure $6 \mathrm{c}$ ). Interestingly, phosphorylation of Akt was enhanced by EGF stimulation in cells bearing the H1047R mutation in p110a, whereas the activation of Akt, in HCT116 WT cells, was not EGF dependent. These observations suggest that WT-p110a and H1047R-p110a may regulate $\mathrm{BCl}-2$ expression by different signaling pathways or mechanisms which need to be further investigated.

The rounded and clumped cell morphology of HCT116 MUT cells was induced by overexpression of BCl-2 (Figure 7a). This suggests that downregulation of $\mathrm{BCl}-2$, in HCT116 MUT cells, probably has an important role in the H1047R mutation-mediated reorganization of the actin cytoskeleton and cell morphologic changes. It has been reported that knockdown of anti-apoptotic $\mathrm{BCl}-2$ proteins directly inhibits the migration and invasion of the CRC cells HT29 and SW480, independent of their cell death induction or effects on proliferation. ${ }^{39}$ However, our results show that overexpression of $\mathrm{BCl}-2$ in HCT116 MUT cells impairs gap closure in a wound-healing assay (Figure 7b). It is known that
SW480 cell line expresses WT PI3K and that HT29 cells bear the $\mathrm{P}_{449 \mathrm{~T}^{\mathrm{b}}}$ mutation in p110a. ${ }^{40}$ All of these observations further indicate the multiple and complex functions of $\mathrm{BCl}-2$ and $\mathrm{PI} 3 \mathrm{~K}$, as well as that different phenotypes of $\mathrm{p} 110 a$ may regulate actin cytoskeleton and cell migration by cooperating with $\mathrm{Bcl}-2$ through different mechanisms.

It is hard to ignore the function of secondary messenger $\mathrm{PIP}_{3}$ Janetopoulos et al. ${ }^{41}$ demonstrated that the regulation of $\mathrm{PIP}_{3}$ has a central role in changing the cell morphology during cytokinesis. It has also been reported that $\mathrm{PIP}_{3}$ has an essential role in many actin-based cellular processes, encompassing cell migration and invasion. ${ }^{42-43}$ Moreover, a recent report demonstrated that the overexpression of a constitutively active form of PI3K, v-P3K, is sufficient to induce the remodeling of actin filaments to form lamellipodia and filopodia in CEF cells. ${ }^{15}$ In the present study, our results clearly confirm that the activation of $\mathrm{PI} 3 \mathrm{~K}$ and intracellular accumulation of $\mathrm{PIP}_{3}$ by $\mathrm{H} 1047 \mathrm{R}$ mutation in $\mathrm{p} 110$ a not only results in elongated cell shape but also significantly changes the actin cytoskeleton structure (Figures 1 and 2). In other words, the H1047R mutation results in the cells gaining many more filopodia filaments. PIP 3 has been shown to accumulate at the tips of filopodia in dendritic cells. ${ }^{44}$ This induced formation of filopodia was reported to be dependent on $\mathrm{PIP}_{3}$ binding via the $\mathrm{PH}$-domain of myosin- $X$, which is primarily found at the tips of filopodia. ${ }^{45}$ 
Filopodia have important roles in sensing extracellular signals, migration and cell-cell interactions. ${ }^{22}$ Moreover, an increased density of filopodia has been described in cancer. ${ }^{46}$ Recent research has shown that filopodia-associated genes are upregulated in breast carcinomas with a poor prognosis, ${ }^{47}$ and that filopodia stimulate cell migration in many cell types. ${ }^{48}$

In conclusion, our findings indicate that the H1047R mutation reorganizes actin structure and in turn results in change of cell morphology. This function possibly contributes to the enhanced migratory capacity of HCT116 MUT cells. Although the underlying mechanism behind the morphological changes is complex, the H1047R-p110a-mediated cell morphological change and enhanced motility in HCT116 cells may be partially caused by the downregulation of the oncogene $\mathrm{Bcl}-2$; and the cellular accumulation of $\mathrm{PIP}_{3}$ may be another import cause by different signaling pathway (Figure 8). Further studies are needed to investigate how the H1047R mutation in p110a causes the downregulation of $\mathrm{BCl}-2$ and to understand the role of $\mathrm{BCl}-2$ and $\mathrm{PIP}_{3}$ in the H1047R mutation-mediated CRC metastasis. Our results further confirmed that the accumulation of $\mathrm{PIP}_{3}, \mathrm{Bcl}-2$ level and change in the appearance of cytoskeleton of cells are important aspects in regulating cell motility and, subsequently, metastasis. Thus, the PI3K pathway remains a desirable target for CRC therapeutics. Our results have implications for ongoing studies using therapeutics targeting both the PI3K/Akt and $\mathrm{Bcl}-2$ pathways.

\section{MATERIALS AND METHODS}

Cell lines and culture medium

The HCT116 WT and HCT116 MUT CRC cell lines engineered to contain either the wild type (WT) or the H1047R mutant (MUT) PIK3CA allele, respectively, were gifts from Dr. Vogelstein and Dr. Velculescu (The Johns Hopkins Kimmel Cancer Center, Baltimore, MD). Both cell lines were generated from the parental cell line HCT116, which possesses both a MUT and WT PIK3CA allele, by targeted deletion of either the MUT or WT PIK3CA locus. ${ }^{6}$ The cells were cultured and maintained in McCoy's $5 \mathrm{~A}$ medium (Sigma, St. Louis, MO, USA) supplemented with $10 \%(\mathrm{v} / \mathrm{v})$ fetal bovine serum at $37{ }^{\circ} \mathrm{C}$ in a humidified atmosphere of $95 \%$ air and $5 \% \mathrm{CO}_{2}$.

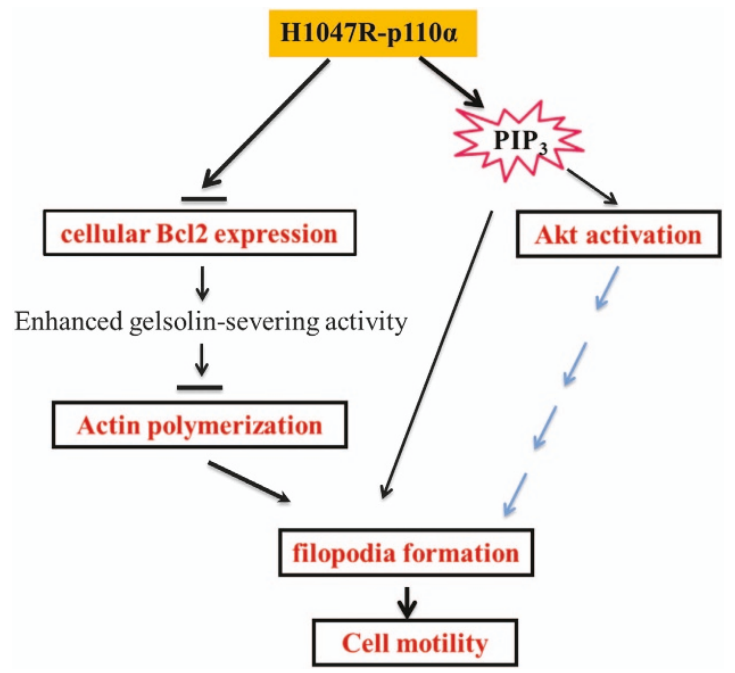

Figure 8. Model for H1047R-p110a-induced morphological change and increased cell motility in HCT116 cells. The H1047R mutation in p110a causes the downregulation of $\mathrm{Bcl}-2$, which results an enhanced gelsolin-severing activity. This blocks actin polymerization, induces reorganization of actin cytoskeleton and increase filopodia formation. Moreover, the accumulation of $\mathrm{PIP}_{3}$ and hyperactivity of Akt may modify the structure of the cytoskeleton by the different mechanisms.
Plasmid constructs

To construct Tet-on $3 \mathrm{G}$ bidirectional-inducible expression plasmids of either WT-p110a or H1047R-p110a, we first amplified the full-length cDNAs (PIK3CA ${ }^{W T}$ or PIK3CA ${ }^{\text {A3140G }}$ ) encoding WT-p110a or H1047R-p110a from total RNA, which were extracted from HCT116 WT and MUT cell, respectively, using the One Step Reverse Transcriptional-PCR Kit (Cat. 210210, QIAGEN, Valencia, CA, USA). The following primers were used for the PCR amplification: forward, 5'- accggggeccagatctATGCCTCCACGACCAT CATCAGG-3' and reverse, 5'-gcggatcgatggatccTCAGTTCAATGCATGCTG-3'. The CDNAs (PIK3CA ${ }^{W T}$ or PIK3CA ${ }^{A 3140 G}$ ) were subsequently cloned into the pTRE3G-bi-mCherry vector using the In-Fusion HD Cloning Kit (PT5162, Clontech, Mountain View, CA, USA). The pCMV-Tet3G, encoding Tet-On 3G transactivator protein, was purchased from Clontech (Cat. 631335).

The pUNO1-hBcl-2 alpha (Cat. Puno1-hbcl2) and the empty pUNO1 vector (Cat. Puno1-mcs) were purchased from InvivoGen (San Diego, CA, USA).

Transfection of LifeAct-GFP, pTRE3G-BI-mCherry/p110a ${ }^{\mathrm{WT}}$, pTRE3G-BI-mCherry/p110a ${ }^{\mathrm{H} 1047 \mathrm{R}}, \mathrm{pUNO} 1$ and pUNO1-hBcl2alpha Lifeact-GFP, as described by Riedl et $a l^{21}$ is a versatile maker comprising a GFP-tagged F-actin-binding domain and can thus be used to visualize actin cytoskeleton in living cells. HCT116 WT and MUT cells were transfected with the Lifeact-GFP-encoding plasmid using the Lipofectamin 2000 transfection reagent (Life Technologies, Cat: 11668-019, Grand Island, NY, USA).

HCT116 WT cells, which have been previously transfected with pCMVTet3G, were transfected with pTRE3G-BI-mCherry/p110a $a^{W T}$ or pTRE3G-BI$\mathrm{mCherry} / \mathrm{p} 110 a^{H 1047 R}$ using the Xfect transfection reagent (Cat. 631317, Clontech)

HCT116 MUT cells were transfected with pUNO1 and pUNO1-hBcl2alpha using the Xfect transfection reagent (Cat. 631317, Clontech).

\section{F-actin staining}

For F-actin labeling, HCT116 WT and MUT cells were grown on coverslips for $24 \mathrm{~h}$. Once at the desired confluence (50-60\%), cells were fixed in $4 \%$ paraformaldehyde (PFA) in PBS for 15 min at room temperature. Following three washes with PBS, cells were permeablized in $0.1 \%$ Triton X-100 in PBS at room temperature for $10 \mathrm{~min}$ and subsequently washed three more times with PBS. Next, cells were incubated with Image-iT FX signal enhancer (136933, Molecular Probe, Carlsbad, CA, USA) for 20-30 min to reduce nonspecific background staining by fluorescently conjugated antibodies or reagents. Following three washes with PBS, cells were incubated in 100-200 $\mu \mathrm{l}$ of $1: 80$ PBS-diluted Alexa Fluor 488 phalloidin (A12379, Invitrogen, Grand Island, NY, USA) for $20 \mathrm{~min}$ in a light-tight covered 6-well plate. Next, the cells were rinsed in PBS and mounted onto glass coverslips using ProLong Gold reagent containing DAPI (P36935, Invitrogen). All steps are at room temperature. The coverslips were stored in the dark at $2-6^{\circ} \mathrm{C}$ until they were imaged.

\section{Imaging}

To characterize the overall cell morphology of living HCT116 parental, WT and MUT cells in the presence or absence of p110a inhibitor, individual images of living cells were captured randomly and in a blinded manner, on a Nikon TE2000 inverted microscope using a $\times 20$ dry objective (Melville, NY, USA). Confocal images of HCT116 Parental, WT and MUT cells, which were fixed and stained for F-actin, were acquired using a Zeiss LSM510 META/Axio Observer confocal microscope (Carl Zeiss, Microimaging, Inc., Thornwood, NY, USA), with a $63 \times 1.4$ NA oil objective. Time-lapse images of live HCT116 WT and MUT cells, transfected with Lifeact-GFP, were acquired with a Zeiss LSM510/Axiovert $200 \mathrm{M}$ confocal microscope using a $\times 40$ W1.1 NA objective.

\section{Filopodia analysis}

The degree of difference between the structures of filopodia in HCT116 WT and MUT cells was assessed using a custom Matlab (R2012b, The Mathworks, Natick, MA, USA) script. The analysis was similar to that performed by Mege et al. ${ }^{23}$ Straight line segments of uniform $5-\mu \mathrm{m}$ length were superimposed along the cell borders. The actual length of the cell border between the start and end points of these line segments was then measured. The ratio between the sum of the lengths of the $5 \mu \mathrm{m}$ line segments and the total cell border length, $R$, is a measure of the surface 
roughness of the cell, which corresponds to the number of filopodia present:

$$
R=\frac{\Sigma \text { Line segment length }}{\Sigma \text { Cell border length }}
$$

Therefore, an $R$-value close to 1 indicates a smooth surface, whereas an $R$-value close to 0 corresponds to a rougher surface.

\section{Immunoblotting analysis}

Total protein concentrations of cell lysates were measured using the Protein Assay kit (Bio-Rad). A total of $20 \mu \mathrm{g}$ of protein was loaded onto a $12.5 \%(\mathrm{w} / \mathrm{v})$ SDS-PAGE gel and transferred onto a nitrocellulose membrane. Antibodies against human p110a (Cell Signaling, Danvers, MA, USA, \#4255), Akt (Cell Signaling, \#9272), Bcl-2 (Cell Signaling, \#2872) and epidermal growth factor receptor (EGFR; Cell Signaling, \#2232) were used for estimating the amount of each protein. The antibodies against Phospho-Akt (Ser473; Cell Signaling, \#9271), phosphor-Akt (Thr308; Cell Signaling, \#9275) and phospho-EGFR (Tyr1045; Cell Signaling, \#2237) at the indicated amino-acid residue sites were employed for determining phosphorylated protein level of Akt and EGFR, respectively.

\section{Flow cytometric analysis of F-actin contents}

F-actin contents of HCT116 parental, WT and MUT cells were measured by Flow-Cytometry (BD LSRFortessa Cell Analyzer, BD Biosciences San Jose, CA, USA). In brief, cells were cultured in a dish to $90 \%$ confluence, trypsinized and subsenquently divided into 2 -ml microtubes $\left(2 \times 10^{6}\right.$ cells per tube), washed with PBS, fixed with $2 \%$ PFA for $1 \mathrm{~h}$ at room temperature, permeabilized with $0.1 \%$ Triton $\mathrm{X}-100$ for $15 \mathrm{~min}$ and stained with Alexa Flour 488-conjugated phalloidin (A12379, Life Technologies) for $20 \mathrm{~min}$ at room temperature. After thorough washing with PBS containing $0.5 \% \mathrm{BSA}$, the cells were analyzed by flow cytometry and data analysis was carried out using Flow Jo (Tree Star Inc., Ashland, OR, USA).

\section{Wound-healing assay}

Cell migration was studied using the scratch wound-healing assay. Four million HCT116 WT or MUT cells were plated into 6-well plates and incubated overnight. A sterile $200-\mu \mathrm{l}$ pipette tip was used to scratch three separate wounds. The cells were gently rinsed with DPBS and further incubated in $2.0 \mathrm{ml}$ of culture medium. The wound closure was measured after 0,6 or 12 , and $24 \mathrm{~h}$ using a Nikon light microscope at $\times 10$ magnification.

\section{PI3K inhibition by A66}

The p110a specific inhibitor A66 (Selleck, Houston, TX, USA, \#S2636) was used to inhibit p110a-PI3K activity. To test the effect of p110a inhibition on cell shape, HCT116 MUT cells were cultured on 18-mm-round coverslips for $18-24 \mathrm{~h}$ and subsequently treated with $1.0 \mu \mathrm{M} \mathrm{A66}$ for $0,6,12$ and $24 \mathrm{~h}$. Following the incubation with the inhibitor, cells were fixed and stained for F-actin. In order to investigate the effect of p110a inhibition on cellular Bcl2 level, HCT116 WT and MUT cells were cultured in 100-mm dish for $24 \mathrm{~h}$, after starved in serum-free medium overnight and before $20 \mathrm{~min}$ stimulation of $100 \mathrm{ng} / \mathrm{ml}$ of EGF, cells were treated for $3 \mathrm{~h}$ with $0,0.1,1.0$ and $10.0 \mu \mathrm{M}$ of $\mathrm{A} 66$, respectively.

\section{Cell morphology analysis}

Quantitative analysis of the cell morphology was based on the method of Analysis of Cell Morphology (http://amrita.vlab.co.in/?sub $=3 \& \mathrm{brch}=$ $278 \& \operatorname{sim}=1465 \& \mathrm{cnt}=1$ ). The area, perimeter and circularity of individual cells were measured using Image J (http://rsb.info.nih.gov/ij/). Cell morphology can be measured as a shape factor (S).

The shape factor $(S)$ is determined using the following equation:

$$
S=\frac{4 \pi A}{P^{2}}
$$

where $A=$ the area of the cell and $P=$ the cell perimeter.

Shape factor values range from 0 to 1 , and measures the circularity or spreading of cells. Circular cells have a shape factor closer to 1, whereas a shape factor closer to 0 is indicative of an elongated cell.
Statistical analysis

Statistical significance was determined using a two-tailed Student's $t$-test with a $P$-value $<0.05$.

\section{ABBREVIATIONS}

PI3K, phosphoinositide 3-kinase; $\mathrm{PIP}_{3}$, phosphatidylinositol (3,4,5)-trisphosphate (Ptdlns $\left.(3,4,5) P_{3}\right) ; B C l-2$, B-cell lymphoma 2; CRC, colorectal cancer; WT, wild type; MUT, mutant; Akt, protein kinase B (PKB) or serine/ threonine-specific protein kinase; EGFR, epidermal growth factor receptor; GFP, green fluorescent protein

\section{ACKNOWLEDGEMENTS}

This work was supported in part by the American Cancer Society-Institutional Research Grants to A Rajput and G Wan as well as the New Mexico Spatiotemporal Modeling Center (NIH P50GM085273). Images in this paper were acquired under the guidance of Dr. Becky Lee and Ms. Genevieve Phillips at the University of New Mexico \& Cancer Center Fluorescence Microscopy Shared Resource facility, and funded as detailed on:http://hsc.unm.edu/crtc/microscopy/acknowledgment.shtml"

\section{COMPETING INTERESTS}

The authors declare no conflict of interest.

\section{REFERENCES}

1 Samuels Y, Wang Z, Bardelli A, Silliman N, Ptak J, Szabo S et al. High frequency of mutations of the PIK3CA gene in human cancers. Science 2004; 304: 554.

2 Vogt PK, Kang S, Elsliger MA, Gymnopoulos M. Cancer-specific mutations in phosphatidylinositol 3 Kinase. Trends Biochem Sci 2007; 32: 342-349.

3 Ikenoue T, Kanai F, Hikiba Y, Obata T, Tanaka Y, Imamura J et al. Functional analysis of PIK3CA gene mutations in human colorectal cancer. Cancer Res 2005; 65: 4562-4567.

4 Kang S, Bader AG, Vogt PK. Phosphatidylinositol 3-kinase mutations identified in human cancer are oncogenic. Proc Natl Acad Sci USA 2005; 102: 802-807.

5 Bader AG, kang S, Vogt PK. Cancer-specific mutations in PIK3CA are oncogenic in vivo. Proc Natl Acad Sci USA 2006; 103: 1475-1479.

6 Samuels Y, Diaz LA Jr, Schmidt-Kittler O, Cummins JM, Delong L, Cheong I et al. Mutant PIK3CA promotes cell growth and invasion of human cancer cells. Cancer Cell 2005; 7: 561-573.

7 Guo X, Rajput A, Rose R, Hauser J, Beko A, Kuropatwinski K et al. Mutant PIK3CAbearing colon cancer cells display increased metastasis in an orthotopic model. Cancer Res 2007; 67: 5851-5858.

8 Kato S, lida S, Higuchi T, Ishikawa T, Takagi Y, Yasuno M et al. PI3KCA mutation is predictive of poor survival in patients with colorectal cancer. Int J Cancer 2007; 121: 1771-1778.

9 Rodriguez-Viciana P, Warne PH, Dhand R, Vanhaesebroeck B, Gout I, Fry MJ et al. Phosphatidylinositol-3-OH kinase as a direct target of Ras. Nature 1994; 370: 527-532.

10 Wennstrom S, Hawkins P, Cooke F, Hara K, Yonezawa K, Kasuga M et al. Activation of phosphoinositide 3-kinase is required for PDGF-stimulated membrane ruffling. Curr Biol 1999; 4: 385-393.

11 Ma AD, Metjian A, Bagrodia S, Taylor S, Abrams CS. Cytoskeletal reorganization by $G$ protein-coupled receptors is dependent on phosphoinositide 3-kinase gamma, a Rac guanosine exchange factor, and Rac. Mol Cell Biol 1998; 18: 4744-4751.

12 Mercurio AM, Rabinovitz I. Towards a mechanistic understanding of tumor invasion-lessons from the $a_{6} \beta_{4}$ integrin. Semin Cancer Biol 2001; 11: 129-141.

13 Khayat ZA, Tong P, Yaworsky K, Bloch RJ, Klip A. Insulin-induced actin filament remodeling colocalizes actin with phosphatidylinositol 3-kinase and GLUT4 in L6 myotubes. J Cell Sci 2000; 113: 279-290.

14 Kotani K, Yonezawa K, Hara K, Ueda H, Kitamura Y, Sakaue H et al. Involvement of phosphoinositide 3-kinase in insulin- or IGF-1-induced membrane ruffling. EMBO J 1994; 13: 2313-2321.

15 Qian Y, Corum L, Meng Q, Blenis J, Zheng JZ, Shi X et al. PI3K induced actin filament remodeling through Akt and p70S6K1: implication of essential role in cell migration. Am J Physiol Cell Physiol 2004; 286: C153-C163.

16 Pollard TD, Cooper JA. Actin, a central player in cell shape and movement. Science 2009; 326: 1208-1212.

17 Pollard TD, Borisy GG. Cellular motility driven by assembly and disassembly of actin filaments. Cell 2003; 112: 453-465.

18 Lambrechts A, Troys MV, Ampe C. The actin cytoskeleton in normal and pathological cell motility. INT J Biochem Cell Biol 2004; 36: 1890-1909. 
19 Yamaguchi $\mathrm{H}$, Condeelis J. Regulation of the actin cytoskeleton in cancer cell migration and invasion. Biochim Biophys Acta 2007; 1773: 642-652.

20 Petrie RJ, Doyle AD, Yamada KM. Random versus directionally persistent cell migration. Nat Rev Mol Cell Biol 2009; 10: 538-549.

21 Riedl J, Crevenna AH, Kessenbrock K, Yu JH, Neukirchen D, Bista M et al. Lifeact: a versatile marker to visualize F-actin. Nat Methods 2008; 5: 605-607.

22 Mattila PK, Lappalainen P. Filopodia: molecular architecture and cellular functions. Nat Rev Mol Cell Biol 2008; 9: 446-454.

23 Mege JL, Capo C, Benoliel AM, Bongrand P. Use of cell contour analysis to evaluate the affinity between macrophages and glutaraldehyde-treated erythrocytes. Biophys J 1987; 52: 177-186.

24 Lee JY, Engelman JA, Cantley LC. PI3K charges ahead. Science 2007; 317: 206-207.

25 Leslie NR, Downes CP. PTEN function: how normal cells control it and tumour cells lose it. Biochem J 2004; 382: 1-11.

26 Chalhoub N, Baker SJ. PTEN and the PI3-Kinase pathway in cancer. Annu Rev Pathol Mech Dis 2009; 4: 127-150.

27 Yu J, Zhang Y, Mcllroy J, Rordorf-Nikolic T, Orr GA, Backer JM. Regulation of the p85/ p110 phosphatidylinositol 3'-kinase: stabilization and inhibition of the p110alpha catalytic subunit by the p85 regulatory subunit. Mol Cell Biol 1998; 18: 1379-1387.

28 Jamieson S, Flanagan JU, Kolekar S, Buchanan C, Kendall JD, Lee WJ et al. A drug targeting only p110a can block phosphoinositide 3-kinase signalling and tumour growth in certain cell types. Biochem J 2011; 438: 53-62.

29 Ke H, Parron VI, Reece J, Zhang JY, Akiyama SK, French JE. BCL2 inhibits cell adhesion, spreading, and motility by enhancing actin polymerization. Cell Res 2010; 20: 458-469.

30 Reinhart-King CA, Dembo M, Hammer DA. The dynamics and mechanics of endothelial cell spreading. Biophys $J$ 2005; 89: 676-689.

$31 \mathrm{Ke} \mathrm{H}$, Zhang JY, Akiyama SK, French JE. BCL2 interaction with actin in vitro may inhibit cell motility by enhancing actin polymerization. Cell Adh Migr 2011; 5: 6-10.

32 Engelman JA, Luo J, Cantley LC. The evolution of Phosphatidylinositol 3-kinase as regulators of growth and metabolism. Nat Rev Genet 2006; 7: 606-619.

33 Friedl $\mathrm{P}$, Wolf $\mathrm{K}$. Tumor-cell invasion and migration: diversity and escape mechanisms. Nat Rev Cancer 2003; 3: 362-374.

34 Yip KW, Reed JC. Bcl-2 family proteins and cancer. Oncogene 2008; 27: 6398-6406.

$35 \mathrm{Mi}$ Z, Mirnics ZK, Schor NF. Bcl-2 overexpression disrupts the morphology of PC12 cells through reduced ERK activation. Brain Res 2006; 1112: 46-55.

36 Pugazhenthi S, Nesterova A, Sable C, Heidenreich KA, Boxer LM, Heasley LE et al. Akt/protein kinase $B$ up-regulates $\mathrm{Bcl}-2$ expression through cAMP-response element-binding protein. J Biol Chem 2000; 275: 10761-10766.
37 llyas M, Hao XP, Wilkinson K, Tomlinson IPM, Abbasi AM, Forbes A. Loss of Bcl-2 expression correlates with tumour recurrence in colorectal cancer. Gut 1998; 43: 383-387.

38 Poincloux L, Durando X, Seitz JF, Thivat E, Bardou VJ, Giovannini MH et al. Loss of $\mathrm{Bcl}-2$ expression in colon cancer: A prognostic factor for recurrence in stage II colon cancer. Surgical Oncology 2009; 18: 357-365.

39 Koehler BC, Scherr A-L, Lorenz S, Urbanik T, Kautz N et al. Beyond cell deathantiapoptotic $\mathrm{Bcl}-2$ proteins regulate migration and invasion of colorectal cancer cells in vitro. PLOS ONE 2013; 8: e76446.

40 Ahmed D, Eide PW, Eilertsen IA, Danielsen SA, Eknæs M, Hektoen M et al. Epigenetic and genetic features of 24 colon cancer cell lines. Oncogenesis 2013; 2: e71.

41 Janetopoulos C, Borleis J, Vazquez F, lijima M, Devreotes P. Temporal and spatial regulation of phosphoinositide signaling mediates cytokinesis. Dev Cell 2005; 8: 467-477.

42 Ridley AJ, Schwartz MA, Burridge K, Firtel RA, Ginsberg MH, Borisy G et al. Cell Migration: Integrating Signals from Front to Back. Science 2003; 302: 1704-1709.

43 Kölsch V, Charest PG, Firtel RA. The regulation of cell motility and chemotaxis by phospholipid signaling. J Cell Sci 2008; 121: 551-559.

44 Luikart BW, Zhang W, Wayman GA, Kwon CH, Westbrook GL, Parada LF. Neurotrophin-dependent dendritic filopodial motility: a convergence on PI3K signaling. J Neurosci 2008; 28: 7006-7012.

45 Plantard L, Arjonen A, Lock JG, Nurani G, Ivaska J, Stromblad S. Ptdlns(3,4,5)P is a regulator of myosin-X localization and filopodia formation. J Cell Sci 2010; 123: 3525-3534.

46 Xue F, Janzen DM, Knecht DA. Contribution of filopodia to cell migration: a mechanical link between protrusion and contraction. Int/ J Cell Biol 2010; 2010: 507821.

47 Zhang H, Berg JS, Li Z, Wang Y, Lang P, Sousa AD et al. Myosin-X provides a motor-based link between integrins and the cytoskeleton. Nat Cell Biol 2004; 6: 523-531.

48 Arjonen A, Kaukonen R, Ivaska J. Filopodia and adhesion in cancer cell motility. Cell Adh Migr 2011; 5: 421-430.

This work is licensed under a Creative Commons Attribution 4.0 International License. The images or other third party material in this article are included in the article's Creative Commons license, unless indicated otherwise in the credit line; if the material is not included under the Creative Commons license, users will need to obtain permission from the license holder to reproduce the material. To view a copy of this license, visit http://creativecommons.org/licenses/ by/4.0/

Supplementary Information accompanies the paper on the Cell Death Discovery website (http://www.nature.com/cddiscovery) 